Issues and Perspectives

\title{
An Evaluation of U.S. National Wildlife Refuge Planning for Off-Road Vehicle Use
}

\author{
Robert L. Fischman,* Vicky J. Meretsky, Katie Freeman, Alexi Lamm, Leah Missik, Scott Salmon \\ R.L. Fischman \\ Maurer School of Law, Indiana University, Bloomington, Indiana 47405
}

V.J. Meretsky

School of Public and Environmental Affairs, Indiana University, Bloomington, Indiana 47405

\section{K. Freeman}

Abercrombie \& Kent Philanthropy, 1411 Opus Place, Downers Grove, Illinois 60532

\section{A. Lamm}

Utah State University, 6605 Old Maine Hill, Logan, Utah 84322

\section{Missik}

Built Green of King and Snohomish Counties, 335 116th Avenue SE, Bellevue, Washington 98004

\author{
S. Salmon \\ Indiana Dept. of Natural Resources, 402 W. Washington Street, Indianapolis, Indiana 46204
}

\begin{abstract}
Off-road vehicles (hereafter, ORVs) rank high among public-land management challenges because they are popular, often impair environmental conditions, and may cause conflicts with other recreational users. Unit-level planning for federal lands increasingly translates broad, system-wide objectives, such as maintenance of ecological integrity, into place-based limitations on ORV use to minimize and mitigate adverse impacts on wildlife. We reviewed 176 planning documents covering 313 National Wildlife Refuges (hereafter, Refuges) to understand how planning supports or undermines ORV recreation management. These plans offer an important perspective on ORV management because the Refuges are a large, diverse system of conservation lands where recreation may be permitted only where it is compatible with wildlife protection. Of the plans we evaluated, $24 \%$ mentioned ORV use and $12 \%$ prescribed some action related to ORVs. The most common prescriptions banned ORV use or limited it to mobility-impaired hunters. Many plans lacked clarity or documentation of analysis in discussing ORV recreation. When analyses grouped ORV use with other activities, such as hunting or other modes of transportation, they often failed to consider the characteristic effects of ORV use. Regardless of how ORV use was categorized, evaluation of its effects seldom considered the full range of environmental impacts documented in the scientific literature. Published research recommends many best practices for managing ORV use and impacts. Though some are habitat specific, five general best-practice categories highlight where planning connects with and diverges from common recommendations. Other land management agencies offer helpful models for implementing these practices in planning. We suggest that public land managers employ tools from each of the five categories: policy formation and public participation, spatial and temporal route planning, permitting, monitoring, and enforcement. The plan prescriptions we examined were strongest in their efforts at route planning. Refuge prescriptions have the most room to improve in detailing how they can work with neighbors and external stakeholders in formulating ORV-use rules.
\end{abstract}

Keywords: conservation planning; off-road vehicle; protected areas; public land management; wildlife refuge Received: May 26, 2016; Accepted: March 6, 2017; Published Online Early: March 2017; Published: June 2017

Citation: Fischman RL, Meretsky VJ, Freeman K, Lamm A, Missik L, Salmon S. 2017. An evaluation of U.S. National Wildlife Refuge planning for off-road vehicle use. Journal of Fish and Wildlife Management 8(1):283-300; e1944-687X. doi:10.3996/052016-JFWM-040

Copyright: All material appearing in the Journal of Fish and Wildlife Management is in the public domain and may be 
reproduced or copied without permission unless specifically noted with the copyright symbol $\odot$. Citation of the source, as given above, is requested.

The findings and conclusions in this article are those of the author(s) and do not necessarily represent the views of the U.S. Fish and Wildlife Service.

* Corresponding author: rfischma@indiana.edu

\section{Introduction}

Since the 1970s, federal land managers have struggled with managing off-road vehicle (hereafter, ORV) recreation. Although ORV use can promote public land objectives, it may also impair resources. Despite executive orders mandating regulations to minimize land damage and wildlife harassment (EO 11644 1972; EO 11989 1977), ORV impacts continue to impair public lands (CRS 2013). Most of the concern about impacts centers on national forest and U.S. Department of the Interior Bureau of Land Management (BLM) lands, where multiple-use mandates and long-standing traditions of ORV recreation can pose significant threats (USDA Forest Service 2006; Switalski and Jones 2008, p. ii). Litigation reflects this focus on multiple-use lands (e.g., U.S. District Court 2012, 2013; Eberle 2015). In contrast, advocates and researchers seldom focus on the dominant-use National Wildlife Refuge System (hereafter, System), which hosts ORV recreation despite its overarching mission to conserve wildlife and plants. Though smaller in scale, ORV recreation in the System nonetheless presents similar environmental problems and planning challenges for controlling use and mitigating harms. The ecological impacts of ORV use have been well-studied. However, less attention has been focused on how public agencies can manage ORV use through planning.

This review examines comprehensive plans governing management of National Wildlife Refuges (hereafter, Refuges, when speaking generally, or NWRs, when referring to specific Refuges). Our objective is to analyze how a federal agency, whose mandate requires written determinations ensuring wildlife conservation before allowing ORV use, grappled with the social and ecological issues surrounding this common recreational activity. In addition to describing the treatment of offroad vehicle use in planning documents, we compare it with best management practices (hereafter, BMPs) recommended in published research. Our ultimate goal is to provide a basis for improving comprehensive plan treatment of ORV use in the next generation of revisions to these binding strategies for managing particular public land units.

This study examined only terrestrial ORVs designed for or capable of travel over land or snow, a scope adapted from the executive orders that guide planning and management. We employ the term "ORV" because it is the longest-standing and generally the broadest, common name for the kinds of recreational vehicles involved in public-land recreation conflicts. For our purposes, ORVs included all-terrain cycles (two-wheel), all-terrain vehicles (three- to six-wheel ATVs), off-highway vehicles (OHVs), utility vehicles, motorcycles, motorbikes, dune buggies, and snowmobiles. Outside of our study domain were vehicles commonly excluded from ORV or (especially in the case of the U.S. Forest Service) OHV categories: Segways; mountain bikes; mopeds designed for road use; motorboats or other forms of transportation designed to travel over swampland, marsh, or bodies of water; and fire, military, emergency or law-enforcement vehicles.

\section{The Refuges}

The U.S. Fish and Wildlife Service (hereafter, FWS) manages the System, with units in all 50 U.S. states as well as in many U.S. territories. Excluding the marine national monuments, Refuges encompass 38 million ha of all major habitat types (USFWS 2015). Refuges are found in urban and suburban areas, agricultural landscapes, and more remote settings. The System faces ORV management issues across the entire range of landscapes managed for nature protection in the United States. Relative to national forests and BLM districts, nonAlaskan Refuges are small but may host up to 20,000 ORV visits/y (Umbagog NWR CCP, p. 3-48). Still, the amount of public controversy affecting Refuge ORV use is small compared with the federal multiple-use lands, where outdoor recreation, broadly defined, is a higher priority objective.

Documentation of particular activities incompatible with wildlife protection on Refuges helped spur 1997 legislation requiring conservation planning for all Refuges (GAO 1981, 1989; Fischman 2003). The 1997 legislation established a System mission of conserving a national network of lands for healthy populations of plants and animals (National Wildlife Refuge System Improvement Act 1997). But, at the same time, Congress also required the FWS to promote and give priority to "wildlifedependent recreation" on Refuges (16 U.S.C. § 668dd), which is defined as hunting, fishing, wildlife observation, wildlife photography, environmental education, and environmental interpretation (16 U.S.C. § 668ee). The FWS, like all federal land agencies, struggles to balance these often competing statutory instructions. Public recreational uses are long-standing on many Refuges and often predate the 1997 mandate for comprehensive, unit-level plans called "comprehensive conservation plans" (hereafter, CCPs). Legislation requires each Refuge unit to be managed "in a manner consistent with" the CCP (16 U.S.C. § 668dd(e)(1)(E)); existing recreational uses 
are subject to the same review requirements during planning as newly proposed uses. Congress gave the FWS 15 years to complete the plans, and the years leading up to the 2012 deadline saw a substantial increase in approved plans. This is the period (1 January 2005-1 January 2012) we examined in our study of planning for ORV management.

The FWS manual sets out the procedure to prepare a CCP and revise it regularly thereafter. Although the manual's planning policy does not discuss ORVs, a checklist of requirements for preparing a CCP includes the 1972 executive order, which mandates zoning areas and trails where ORVs may and may not be used (602 FW 3 exhibit 2). The FWS has reserved a manual chapter to govern ORV use on Refuges, but has not yet promulgated content for it (632 FW 2). In general, Congress closed the System to all recreational uses unless specifically opened in particular areas by FWS regulation (16 U.S.C. § 668dd(c) \& (d)). The 1982 Refuge manual chapter on public use provides a modicum of guidance on ORV management, particularly on the findings necessary to permit ORV uses, and zoning of areas for them (8 Refuge Manual 7). A 2006 memorandum from the director of the FWS noted that many of the 75 Refuges reporting ORV use had failed to comply with the executive orders and FWS policies. It therefore prohibited Refuge managers from authorizing any new ORV uses (either individually or as a component of another use) until the publication of new regulations and policy (USFWS 2006). Such publication has not yet occurred.

\section{Environmental impacts of ORVs}

Off-road vehicle use is one of the fastest-growing forms of public land recreation in the United States (Davenport and Switalski 2006). One widely cited study estimated there were $>10$ million snowmobile and wheeled, off-road vehicles in the United States in 2008 (Cordell et al. 2008). Nearly $20 \%$ of the U.S. population over the age of 16 participates in off-road vehicle recreation, averaging $28 \mathrm{~d}$ of use/y (Cordell et al. 2008). Off-road vehicles can travel quickly and far; monitoring and enforcement is therefore difficult and expensive for public-land managers, who face flat or declining budgets (Archie 2007). These land managers increasingly rely on planning to develop site-specific strategies to manage ORV activity. Although illegal ORV use is also a problem, damage may result from failure to provide adequate protection to wildlife in the prescriptions employed to manage legal use.

As with all uses of Refuges, ORV operations have varying impacts depending on the level and characteristics of the use, and environmental conditions (Stokowski and LaPointe 2000). In some places and at some use levels, ORV use produces minimal harm. However, compared with other forms of recreation, such as hiking or bicycling, ORVs may have a greater impact on the natural landscape and health of the environment (Switalski and Jones 2008). Documented impacts on
Refuges include damage to soil, vegetation, wildlife, and cultural resources, as well as interference with other forms of recreational enjoyment (GAO 2009).

Recreational ORV activity can kill wildlife directly through collision but may also disturb animals by increasing stress and decreasing reproduction (Havlick 2002). In addition, ORVs increase access for illegal hunting (Switalski and Jones 2012). But habitat modification poses a more common threat to wildlife. Soils are vulnerable to compaction and erosion from ORV use. Erosion in the form of mud holes and gullies causes sediment to be discharged to streams, decreasing water quality, destroying in-stream habitat, and harming aquatic organisms (Switalski and Jones 2012; Marion et al. 2014). In addition, oil and gasoline from ORVs can enter soil and waters on public lands (Havlick 2002). Offtrail ORV use may destroy vegetation and impair wildlife habitats. Surviving plants are often weakened and become more susceptible to diseases and insects. Diversity of vegetation often decreases and sensitive species die out, allowing invasive species to take over. Recreational use of ORVs also contributes to the spread of invasive species by transporting seeds and plant materials (Switalski and Jones 2012; Banha et al. 2014). Some ORV trails act as barriers to animal movement and create fragmentation effects (Trombulak and Frissell 2000). Snowmobiles may destroy the habitat of the mammals living under the snow, and engine noise stresses larger mammals (Stokowski and LaPointe 2000). Wheeled ORVs on beaches have been shown to adversely impact birds and crustaceans (e.g., Melvin et al. 1994; Lucrezi et al. 2014).

On the other hand, ORV recreation also generates benefits-both to ORV users and to Refuges (Deisenroth et al. 2009; Jakus et al. 2010). It can facilitate the wildlifedependent activities that Congress instructed Refuges to promote. The use of ORVs may better distribute hunters, increasing safety and the quality of the hunting experience. In the case of people with disabilities, ORV use may be necessary for promoting wildlife-dependent recreation and complying with the Americans with Disabilities Act (42 U.S.C. ch. 126). Users report that ORV recreation connects them with nature, facilitates special activities in nature (such as hunting and fishing), and provides close access for wildlife observation (Mann and Leahy 2010). These pursuits are consistent with the goals of the System and the establishment purposes of many Refuges. However, ORV activity may create conflicts with other outdoor recreationists, often through vehicle noise and intrusion (Adams and McCool 2009).

\section{Standards and procedures for evaluating ORV use in Refuges}

Refuge managers commonly employ ORVs to engage in conservation and public safety activities. Such management-related activities are permitted without formal scrutiny (50 C.F.R. $\S 25.12$ ). In contrast, ORV recreation - the focus of our study_does require formal 
Table 1. Breakdown of formal appropriate and inappropriate findings for off-road (ORV) vehicle use from the 21 Comprehensive Conservation Plans (CCPs) written for national wildlife refuges in 2005-2011 that included findings of appropriateness related to ORV use on the relevant U.S. Fish and Wildlife Service Form 3-3219. Of the 185 CCPs written in this period, 42 mentioned ORV use in some way. In addition to the 21 formal findings of appropriateness included here, 2 additional CCPs indicated ORV use was appropriate but did not include formal findings of appropriateness. For purposes of this study, ORVs included two- to six-wheel allterrain vehicles, off-highway vehicles, utility vehicles, motorcycles, motorbikes, dune buggies, and snowmobiles.

\begin{tabular}{|c|c|c|}
\hline $\begin{array}{l}\text { ORV use found } \\
\text { appropriate } \\
(n=9)\end{array}$ & $\begin{array}{l}\text { ORV use found } \\
\text { not appropriate } \\
\quad(n=12)\end{array}$ & Question receiving a response of "yes" \\
\hline$\overline{9}$ & 12 & (a) Do we have jurisdiction over the use? \\
\hline 9 & 10 & (b) Does the use comply with all applicable laws and regulations? \\
\hline 9 & 5 & (c) Is the use consistent with applicable Executive orders and Department and Service policies? \\
\hline 9 & 3 & (d) Is the use consistent with public safety? \\
\hline 9 & 0 & $\begin{array}{l}\text { (e) Is the use consistent with refuge goals and objectives in an approved management plan or other } \\
\text { document? }\end{array}$ \\
\hline 8 & 8 & $\begin{array}{l}\text { (f) Has an earlier documented analysis not denied the use or is this the first time the use has been } \\
\text { proposed? }\end{array}$ \\
\hline 9 & 1 & $\begin{array}{l}\text { (g) For uses other than wildlife-dependent recreational uses, is the use manageable within available } \\
\text { budget and staff? }\end{array}$ \\
\hline 9 & 2 & (h) Will the use be manageable in the future within existing resources? \\
\hline 9 & 2 & $\begin{array}{l}\text { (i) Does the use contribute to the public's understanding and appreciation of the refuge's natural or } \\
\text { cultural resources, or is the use beneficial to the refuge's natural or cultural resources? }\end{array}$ \\
\hline 9 & 0 & $\begin{array}{l}\text { (j) Can the use be accommodated without impairing existing wildlife-dependent recreational uses or } \\
\text { reducing the potential to provide quality, compatible, wildlife-dependent recreation into the future? }\end{array}$ \\
\hline
\end{tabular}

scrutiny. Long-standing uses often developed on Refuge lands before the FWS considered their impacts. On some Refuges, the preparation of the CCP under the 1997 legislation was the first serious examination of ORV impacts.

The process of evaluating the acceptability of a recreational activity on a Refuge begins with the question of "appropriateness." The congressional preference for wildlife-dependent recreation means that it is always appropriate on Refuges. In contrast, ORV use that is not part of a wildlife-dependent recreational activity requires an administrative finding of appropriateness, on a Refuge-by-Refuge basis. Most Refuges did not undertake the appropriate-use analysis until they prepared their CCPs.

The FWS created the appropriate-use findings as a way of setting priorities among competing uses (603 FW 1). The 2006 policy sets out 10 criteria (listed in the third column of Table 1) for appropriate-use finding. To be considered appropriate, a use must meet the first four criteria: safe, legal, under the control of the Refuge, and consistent with relevant executive orders and policies. Negative findings for any of the remaining six appropriateness criteria do not result in automatic refusal, but FWS policy indicates that they generally result in an inappropriate finding (603 FW 1.11B). The availability of alternative nearby locations for nonwildlife-dependent activities is also a relevant consideration (603 FW 1.11B).

If an ORV use is categorically appropriate or is determined to be appropriate, the FWS then decides whether it is "compatible" on a Refuge-by-Refuge basis (16 U.S.C. $§ 668 d d(d)$ ). A compatible use is one that "will not materially interfere with or detract from the fulfillment of the mission of the System or the purposes of Refuge" (16 U.S.C. $\S$ 668ee). The compatibility determination largely fulfills the 1977 executive order's criterion that ORVs may be permitted only if they "will not adversely affect" natural values (E.O. 11,989 1977, § 4). But the executive order requires a determination that the ORV use will not adversely affect aesthetic and scenic values as well. The burden of showing compatibility rests with the proponent of a use (USFWS 2000, p. 62,489); but, particularly for wildlife-dependent recreation and uses already occurring in 1997, the FWS often makes a compatibility determination on its own initiative. Whereas the FWS devised the appropriate-use finding, Congress required compatibility determinations (16 U.S.C. § $668 d d(d))$.

The FWS currently applies the appropriate-use analysis as an initial filter to determine whether to move forward with the more detailed compatibility determination for nonwildlife-dependent recreation. If the appropriateness review finds a practice inappropriate, the review stops and the use is barred from the Refuge. If a use is appropriate, then the FWS prepares a compatibility determination. The appropriateness test considers the broad characteristics of the use, whereas the compatibility determination focuses tightly on the impact of the use. Because the purposes and environmental contexts of Refuges vary, the appropriateness and compatibility of 
Table 2. Breakdown of the 42 Comprehensive Conservation Plans (CCPs) written in 2005-2011 that mention issues related to offroad vehicle (ORV) use, by year and U.S. Fish and Wildlife Service region. A total of 185 CCPs were written in this period. Where present, data after slashes indicate the number or proportion of CCPs that discuss ORV issues that also contain one or more prescriptions for actions addressing ORV use. For purposes of this study, ORVs included two- to six-wheel all-terrain vehicles, offhighway vehicles, utility vehicles, motorcycles, motorbikes, dune buggies, and snowmobiles.

\begin{tabular}{|c|c|c|c|c|c|c|c|c|c|c|}
\hline Region & 2005 & 2006 & 2007 & 2008 & 2009 & 2010 & 2011 & $\begin{array}{l}\text { Total CCPs that } \\
\text { discuss ORVs }\end{array}$ & $\begin{array}{l}\text { Total CCPs } \\
\text { examined }\end{array}$ & $\begin{array}{c}\% \text { of CCPs } \\
\text { examined that } \\
\text { discuss ORVs }\end{array}$ \\
\hline Pacific NW \& Pacific Islands & 0 & 0 & $2 / 2$ & 0 & 0 & 0 & $2 / 1$ & $4 / 3$ & 23 & $17 / 13$ \\
\hline Southwest & 0 & 0 & 0 & 0 & 0 & $1 / 1$ & 0 & $1 / 1$ & 9 & $11 / 11$ \\
\hline Midwest & 1 & 0 & 1 & 0 & 0 & $1 / 1$ & 0 & $3 / 1$ & 17 & $18 / 6$ \\
\hline Southeast \& Caribbean & 0 & $2 / 2$ & $5 / 2$ & $4 / 1$ & $4 / 2$ & 3 & $3 / 1$ & $21 / 8$ & 76 & $28 / 11$ \\
\hline Northeast & 0 & $3 / 3$ & 1 & 0 & $2 / 2$ & 2 & $2 / 2$ & $10 / 7$ & 22 & $45 / 32$ \\
\hline Mountain-Prairie & 0 & 0 & 1 & 0 & 0 & 0 & 0 & $1 / 0$ & 16 & 6 \\
\hline Pacific Southwest & 0 & 0 & 0 & 0 & $1 / 1$ & 1 & 0 & $2 / 1$ & 13 & $15 / 8$ \\
\hline Total CCPs that discuss ORVs & 1 & $5 / 5$ & $10 / 4$ & $4 / 1$ & $7 / 5$ & $9 / 2$ & $7 / 4$ & $42 / 21$ & & \\
\hline Total CCPs examined & 16 & 36 & 25 & 27 & 25 & 28 & 19 & & 176 & \\
\hline$\%$ of CCPs examined that discuss ORVs & $6 / 0$ & $14 / 14$ & $40 / 16$ & $15 / 4$ & $28 / 20$ & $32 / 7$ & $36 / 21$ & & & $24 / 12$ \\
\hline
\end{tabular}

identical nonwildlife-dependent recreational activities may vary from Refuge to Refuge. The FWS has committed to include the documentation for any appropriateness findings and compatibility determinations in each CCP (603 FW 1.9(A)).

\section{Plan Review}

We examined all 176 CCPs completed between the beginning of 2005 and 2012, except 4 that covered only wetland management districts and 9 in Alaska (Meretsky and Fischman 2014). We excluded the Alaska Refuges from this study because they are subject to the Alaska National Interest Lands Conservation Act, which protects subsistence and traditional activities often conducted with ORVs (16 U.S.C. $\S \S 3113,3114 ; 50$ C.F.R. $\S 36.12$ ). The ORV issues on Alaska Refuges are unique because of this law and the relatively roadless condition of the lands.

We further analyzed the 42 CCPs that mentioned ORVs, and their environmental impact analyses as required under the National Environmental Policy Act (hereafter, NEPA; 16 U.S.C. §§ 4321-4333). For each of these CCPs, we noted whether they found ORVs to be appropriate or compatible; whether they included information on the 10 criteria needed for appropriateness findings; and whether they addressed ORV use in the goals, objectives, and implementation strategies (which we group under the term "prescriptions") of a CCP (Workbook S1 in Supplemental Material Table S1). The prescriptions of the CCP most directly govern management of the Refuges. In addition to the quantitative data from coding the CCPs, we also analyzed the substantive prescriptions for ORV use and mitigation. We matched this qualitative analysis to the existing literature to illustrate how BMPs for ORV use are implemented in resource management plans. By organizing the practices along the lines of the literature, we are able to make categorical recommendations, discussed in the final section of this review.

The 176 CCPs we evaluated covered 313 (58\%) of the 539 Refuges in existence outside of Alaska at the time. Of these CCPs, 42 (24\%) mentioned ORV use (Table 2). Of these 42 CCPs, 21 (50\%; 12\% of the CCPs evaluated) contained one or more prescriptions for action related to ORVs. The other CCPs mentioned ORVs only as a concern or as part of the description of the Refuge environment. Where a CCP raised concerns about vehicular trespass, we made a determination based on the context of the statement as to whether it addressed ORV issues. The proportion of CCPs evaluated that mentioned ORVs increased fairly consistently during the study period (Table 2); the proportion using prescriptions to address ORVs showed a much less consistent trend. Proportions of CCPs mentioning ORVs ranged from 6 to $45 \%$ of the CCPs evaluated by region. More than two-thirds (74\%) of the CCPs that mentioned ORV issues were from the easternmost regions, where national surveys show the majority of ORV recreation occurs (Cordell et al. 2013). Thirteen CCPs cited illegal use, which included off-trail use on Refuges that allow ORVs on trails, as well as trespassing from adjacent lands.

\section{Permissibility of ORV use}

The most common CCP permissibility category is a ban on ORV recreation. However, there exists a continuum of restrictions from a blanket prohibitions to permitting nonwildlife-dependent recreational uses. The least restrictive end of the continuum is constrained by the System-wide prohibition on off-trail use outside of Alaska (50 C.F.R. § 27.31). Among the 42 CCPs mentioning ORV use, 4 discussed both wheeled ORVs and snowmobiles. Where the CCPs provided separate documentation for these different uses within the covered Refuges (i.e., different findings of appropriateness, different compatibility determinations), we analyzed these issues separately. Of the 46 ORV uses considered in the CCPs, we found 4 clear and 2 unclear categories of permissibility of ORV use (Table 3). When a CCP had two levels of permissibility for the same use (e.g., permitting ORVs for hunting but not for wildlife observation), we used the most permissive level to represent the CCP. Most restrictive among the clear categories was an outright 
Table 3. Prescriptions for off-road vehicle (ORV) use in the 42 Comprehensive Conservation Plans (CCPs) written for national wildlife refuges in 2005-2011 that address ORV use, broken down by the level of permissibility of ORV use. Four CCPs addressing ORVs addressed both wheeled ORVs and snowmobiles; permissibilities for all uses are represented here. For purposes of this study, ORVs included two- to six-wheel allterrain vehicles, off-highway vehicles, utility vehicles, motorcycles, motorbikes, dune buggies, and snowmobiles.

\begin{tabular}{lrcr}
\hline & \multicolumn{3}{c}{ Prescription } \\
\cline { 2 - 4 } Permissibility category & No & Yes & Total \\
\hline Ban & 13 & 8 & 21 \\
Mobility-impaired users & 5 & 0 & 5 \\
Wildlife-dependent recreation & 0 & 7 & 7 \\
Other recreation & 0 & 1 & 1 \\
Generally unclear & 2 & 4 & 6 \\
Unclear mobility-impaired & 2 & 4 & 6 \\
Total & 22 & 24 & 46 \\
\hline
\end{tabular}

ban on ORV use, or restriction to roads open for ordinary passenger vehicles. We found bans in 21 CCPs (50\%) covering 22 of 46 uses (48\%; Table 3). Eighteen CCPs (43\%) allowed ORVs only for wildlife-dependent recreation of some kind, or by some groups. One CCP unambiguously permitted ORV access for nonwildlifedependent recreation (recreational snowmobiling in Umbagog NWR; 2\%). Even this least restrictive category of ORV use limits recreationists to designated trails.

In 11 out of the 42 CCPs, the permissibility of a category of ORV use was ambiguous on the face of the document (Table 3). In 6 of these cases, it was unclear whether mobility-impaired hunters might be permitted to rely on ORV use for access. For instance, the Turnbull NWR CCP states in its compatibility determination for elk hunting that "access will be walk-in only except upon special request to reasonably accommodate disability." Although the statement implies ORV access might be acceptable, without a definitive statement clarifying the exception, we categorize this type of language as ambiguous with regard to whether the CCP bans ORVs or allows them for mobility-impaired hunters. In the remaining five ambiguous cases, the permissibility of
ORV use of any kind was undeterminable. Hobe Sound NWR CCP, for example, mentioned ORVs only in a habitat-management objective "Prevent habitat destruction from all-terrain vehicles through enhanced law enforcement." No CCP language indicated a ban on ORVs, listed permissible uses, or provided any determinations as to use. Congress closed all Refuges to public uses unless the FWS affirmatively permits the activity; therefore, we assume that these ambiguous plans intend to prohibit ORV recreation.

Among the four clear categories of permissiveness, all regions used bans most often, or equally with the next most common level of permissibility (Table 4). The Northeast region had the highest number and proportion of CCPs with bans on ORVs. The Southeast and Caribbean region had the highest number and proportion of CCPs allowing use of ORVs.

Overall, only half of CCPs discussing ORVs included prescriptions for addressing their use (Table 3). Among the four CCPs that addressed both snowmobile and ATV issues, two had prescriptions for both uses (Tamarac NWR and Umbagog NWR), one only for ATV use (Canaan Valley NWR), and one for neither use (Missisquoi NWR). Prescriptions addressing ORV use appeared in all of the 7 CCPs allowing ORV use for wildlife-dependent recreation, and in 8 of 21 CCPs that banned ORVs. Four of the seven CCPs allowing ORV use for wildlife-dependent recreation permitted ORV use only in support of hunting or of hunting and fishing. Two CCPs explicitly permitted ORV use for wildlife-dependent activities of any kind (Tensas River NWR and Red River NWR); one permitted ORV use for hunting and fishing and was ambiguous about ORV use for wildlife observation and photography (Catahoula NWR).

\section{Additional NEPA analysis}

Apart from the considerations required as part of the adoption of a CCP, NEPA provides an additional requirement for the FWS to conduct a comprehensive environmental impact analysis of any proposed action. The NEPA analysis may be satisfied with an environmental assessment concluding that adoption of the CCP will

Table 4. Permissibility of off-road vehicle (ORV) use in the 42 Comprehensive Conservation Plans (CCPs) written for national wildlife refuges in 2005-2011 that address ORV use, broken down by U.S. Fish and Wildlife Service region. Out of the 42 CCPs that addressed ORV use, 4 discussed both wheeled ORVs and snowmobiles; permissibilities for both uses are included here. For purposes of this study, ORVs included two- to six-wheel all-terrain vehicles, off-highway vehicles, utility vehicles, motorcycles, motorbikes, dune buggies, and snowmobiles.

\begin{tabular}{|c|c|c|c|c|c|c|c|c|}
\hline \multirow[b]{2}{*}{ Permissibility } & \multicolumn{8}{|c|}{ US Fish and Wildlife Service Region } \\
\hline & $\begin{array}{l}\text { Pacific NW \& } \\
\text { Pacific Islands }\end{array}$ & Southwest & Midwest & $\begin{array}{c}\text { Southeast \& } \\
\text { Caribbean }\end{array}$ & Northeast & Mountain-Prairie & $\begin{array}{c}\text { Pacific } \\
\text { Southwest }\end{array}$ & Total \\
\hline$\overline{\text { Ban }}$ & 3 & 0 & 1 & 7 & 9 & 0 & 2 & 22 \\
\hline Mobility-impaired users & 0 & 0 & 1 & 4 & 0 & 0 & 0 & 5 \\
\hline Wildlife-dependent recreation & 0 & 0 & 0 & 7 & 0 & 0 & 0 & 7 \\
\hline Other recreation & 0 & 0 & 0 & 0 & 1 & 0 & 0 & 1 \\
\hline Generally unclear & 0 & 1 & 0 & 3 & 1 & 0 & 0 & 5 \\
\hline Unclear re mobility-impaired users & 1 & 0 & 2 & 0 & 2 & 1 & 0 & 6 \\
\hline Total & 4 & 1 & 4 & 21 & 13 & 1 & 2 & 46 \\
\hline
\end{tabular}


Table 5. Off-road vehicle (ORV) impacts mentioned in environmental impact statements and environmental assessments for the 42 of 185 Comprehensive Conservation Plans (CCP) completed for national wildlife refuges during 2005-2011 that addressed ORV impacts. Mentions were counted from all parts of the environmental analysis, including public comments. Impacts are ranked in order of number of mentions; multiple mentions of an impact could and did occur in a single CCP. For purposes of this study, ORVs included two- to sixwheel all-terrain vehicles, off-highway vehicles, utility vehicles, motorcycles, motorbikes, dune buggies, and snowmobiles.

\begin{tabular}{lc}
\hline ORV impacts & $\begin{array}{c}\text { No. of documents } \\
\text { mentioning the topic, } \\
\text { out of }\end{array}$ \\
\hline Wild documents
\end{tabular}

not constitute a major federal action significantly affecting the human environment, or with an environmental impact statement documenting the significant environmental effects. Typically, a CCP complied with NEPA through an environmental assessment unless it proposed wilderness, identified significant impacts, or made a particularly controversial decision (602 FW 3; USFWS 2014). The FWS prepared environmental impact statements for only 21 of the 185 CCPs we reviewed, and for only 3 of the 42 CCPs discussing ORV issues (Workbook S2 in Supplemental Material Table S1). Because the three final environmental impact statements contained substantively the same analyses as the matching final CCPs, the additional material that NEPA analyses contributed to our results was from the environmental assessments, which were prepared as part of the draft CCPs considering multiple, alternative directions for managing Refuges.

Twenty-nine NEPA analyses included some mention of ORV impacts (Table 5). Most mentions were related to potential take or disturbance, or harm to habitat or vegetation. Although we found $>100$ mentions of ORV impacts among the 42 NEPA analyses, they were all brief and unspecific. One of the most specific examples, tallied under "wildlife take and disturbance" in Table 5, states simply and entirely: "The presence of ORVs is disruptive to wildlife" (Ellicott Slough NWR CCP, p. 2-4). The NEPA analyses did not expand on or deepen discussions beyond what was in the CCPs and their various appendixes; rather, the few detailed explorations of ORV impacts to Refuge resources were in compatibility determinations. However, as we note below, only 23 of the 185 CCPs we examined included a compatibility determination covering ORV use.

\section{Appropriateness and Compatibility of ORV Use}

The heart of ORV impact analysis in the CCPs was the material describing how the FWS made appropriate-use findings and compatibility determinations. The FWS policies and rules require it to sometimes employ appropriate-use evaluations and always conduct compatibility determinations in deciding whether and how to allow ORV recreation on Refuges. It need not employ these tools in situations where ORV use does not exist or where the public has not requested that a Refuge allow new ORV use. Moreover, the FWS need not prepare findings and determinations when it decides not allow a use. Both procedures require an initial decision about which uses to consider together and which uses belong in their own, separate analyses. Where a CCP considered ORV use as a component of hunting, the impacts of the ORV use generally received less scrutiny and eluded an appropriateness determination. Where the CCPs substantively evaluated ORV recreation, the compatibility determinations largely failed to comply with FWS guidance; they did not grapple with specific adverse environmental impacts documented in the scientific literature.

Nine of the 21 appropriateness evaluations reached affirmative conclusions, and all but 1 of those 9 found all 10 appropriateness criteria to be met; 1 appropriateness finding was affirmative despite a previous negative finding (Table 1). Three CCPs found ORV use inappropriate where it met the four required criteria but did not meet some or all secondary criteria. The remaining nine CCPs that found ORV use inappropriate indicated it failed at least one of the four required criteria. For the 12 CCPs in which ORV use was found inappropriate, safety was the most common required criterion the use failed ( $n=$ 9), followed by consistency with relevant executive orders and policies ( $n=7$; Table 1). Among the six criteria that are not strictly required for appropriateness, lack of consistency with Refuge goals and objectives, and anticipated impairment of wildlife-dependent recreation were failings in all 12 cases in which the FWS found ORV use inappropriate.

Compatibility determinations related to ORV use appeared in 23 CCPs, 2 of which had separate compatibility determinations for wheeled ORVs and for snowmobiles. Thus, we tallied 25 determination outcomes of separate ORV uses. Thirteen CCPs representing 14 uses had multiple relevant compatibility determinations for a given use. Of these 14 uses, 5 had disparate compatibility findings; for example, finding ATVs compatible for mobility-impaired hunters but not for photography (e.g., Central Arkansas NWR Complex 
(CP), or finding ATVs compatible on one Refuge within the multi-Refuge CCP but not on another (e.g., again, the Central Arkansas NWR Complex CCP). Such disparate findings are unsurprising given the range of activities and landscape contexts often covered in a single CCP. In total, the CCPs contained 8 compatibility determinations considering ORVs alone, 20 compatibility determinations (from 17 CCPs) considering ORVs as an aspect of wildlifedependent recreational activities (all but 2-Back Bay NWR and Laguna Atascosa NWR CCPs-as an aspect of hunting), and 4 grouping ORVs with nonwildlife-dependent activities, such as walking or public access.

Though no findings or determinations are required, 11 of 22 banned uses were accompanied by an appropriateness finding, and 7 included $\geq 1$ compatibility determinations. Documentation of compatibility was missing in all five cases in which permissibility of ORV use was considered generally uncertain, and in one case in which ORV use was permitted. Documentation did not necessarily lead to clarity with respect to permissibility. For example, five of six cases of uncertainty regarding the permissibility of ORV use to support mobilityimpaired users resulted from ambiguous language in compatibility determinations. On the other hand, clear permissibility did not guarantee appropriate documentation. For example, the Crab Orchard NWR CCP expressly permitted ORV use without any of the required supporting documentation.

\section{Grouping of ORV use with other activities}

Among the CCPs that contained appropriateness findings and compatibility determinations, some reviewed broad categories of ORV use in a single finding or determination, whereas others considered each mode of transportation or activity separately. Wildlife-dependent recreation need not go through the appropriateness evaluation, so appropriate-use findings were more likely to focus solely on ORV use (20 of 21 uses) than compatibility determinations, in which only 4 of 25 uses addressed ORV use per se, alone. For instance, the Central Arkansas NWR Complex CCP nested ORV use within its hunting compatibility determination, which was a common approach. It did not disaggregate the different impacts from different modes of access for hunting, listed as walking, motor vehicle, boat, bicycle, and ATV. The compatibility determination did, however, call for monitoring of ATV use to protect Refuge resources.

Other CCPs show evidence of a thorough consideration of ORV use even when the analysis bundled it with other forms of recreation. For instance, the Pocosin Lakes NWR CCP found boats, bicycles, wheelchairs, horses, and ORVs appropriate and subsequently compatible in one category, "access for public uses." But the determination applied different limits to different modes of access, and allowed ATV use only in support of hunting. Still others disaggregated the ORV findings from other forms of recreation. For instance, the Carolina Sandhills NWR CCP separated its outdoor recreation category of "bicycling, hiking, jogging, walking, mountain biking, and picnick- ing" from off-road vehicles. The Umbagog NWR CCP went a step further on the continuum by separating out "ATV, ORV, or Motorbike Use," "Snowmobiling and recreational dogsledding on snowmobile trails," bicycling, and horseback riding into 4 different categories, each with its own separate determination.

Nonmotorized recreation, such as hiking, biking, and horseback riding, can adversely affect wildlife conservation (Reed and Merenlender 2008). But clustering ORV recreation with other uses within appropriateness findings and compatibility determinations may shield the ORV-specific impacts from scrutiny. For groupings in which the environmental effects are similar (e.g., walking, running, and jogging), the rationale for the cluster and joint findings is apparent. However, in other cases, different recreational activities generate different types and intensities of impacts. Horses, for example, impact the environment to a greater extent than mountain bikers or walkers, because of the greater weight of the horse, effects of grazing, and nutrient input from manure (Pickering et al. 2010). The ability of ORVs to travel at high speeds over longer, more remote distances-in combination with higher pressure and torque applied to the ground-can produce greater environmental impacts on the environment than hiking or bicycling (Monz et al. 2010). The magnitude of such differences in impact can be a good guide to deciding whether to group together activities in appropriateness and compatibility determinations.

The common practice of including ORV use as part of hunting uses does not necessarily preclude careful analysis of impacts of the ORV component of the recreational activity. But lumping ORV use with hunting may tempt managers to inadequately consider the attributes of ORV use itself, and how it might fit within the objectives of a Refuge. Updated guidance, replacing the 1982 ORV policy superseded by the Fish and Wildlife manual, would improve consistency and ensure proper evaluation of the appropriateness of ORV use on Refuges. The FWS director in 2006 announced the development of new ORV regulations and a revised policy (USFWS 2006). But the administrative process apparently has stalled, which leaves the 1982 policy (8 Refuge Manual 7.2) still in effect except for the moratorium on new uses. We recommend that updated guidance clearly direct Refuge managers to separate the ORV dimension of use analyses, particularly when hunting objectives, such as dispersion of hunters, is not at issue. Also, as the Canaan Valley NWR demonstrated, Refuge-support alternatives to ORV-assisted hunting may sometimes be feasible because of the limited seasons during which users historically employed ORVs.

If the FWS were to draft the next generation of CCPs with greater consistency in categorizing ORV use, then it could more easily monitor compliance with the scrutiny required under the Refuge management policies. It might also aid ORV user groups and other stakeholders to more effectively engage with the FWS. However, 
consistency does not automatically lead to better analysis. Some unwieldy compatibility groupings we encountered nevertheless displayed great attention to detail of all the relevant aspects of ORV impacts (e.g., Pocosin Lakes NWR CCP). Conversely, other determinations that focused solely on ORVs nonetheless provide very little evaluation of potential impacts. Ultimately, the FWS will need to improve its substantive analyses, however it decides to group activities for appropriateness and compatibility evaluations.

\section{Substantive evaluations of ORV impacts}

The failure to account for the full range of site-specific, potential environmental harms is the single greatest shortcoming in most CCP evaluations of ORV impacts. An unusually stringent provision of FWS policy finds incompatible all uses that managers "reasonably may anticipate to reduce the quality or quantity or fragment habitats" on a Refuge (USFWS 2000, p. 62,486). Linear features, such as ORV routes, may be especially vulnerable to this trigger (Trombulak and Frissell 2000), although we did not see it evaluated in the CCPs-only one mentioned the issue (Table 5). The lack of concern about fragmentation betrays a larger blind spot in the CCPs' ORV use analyses: they seldom evaluate the full range of environmental impacts documented in the scientific literature. For instance, the CCPs that approved ORV use for hunting generally justified them as a means to achieve a well-distributed ungulate harvest. Yet the studied CCPs rarely balanced the benefits of better distribution of hunters against such problems as soil compaction, invasive species propagation, and habitat destruction. One rare example of such an analysis is found in the Theodore Roosevelt NWR Complex CCP compatibility determination.

Also generally lacking in hunting compatibility determinations that authorize ORV access is the impact on the experience of other hunters seeking solitude or a more challenging experience, or on Refuge visitors pursuing other recreational uses. No CCP in our study considered the protection of aesthetic values, as required by the executive orders. The FWS policy on hunting in Refuges promotes the provision of "quality" hunting experiences (605 FW 2), but does not define the term. Nonetheless, the FWS' general guidelines for wildlife-dependent recreation do instruct Refuge managers to "concentrate resources on fewer, quality opportunities rather than offer many opportunities that lack quality" (605 FW 1.10(A)).

One approach to minimize the negative effects of ORV-aided hunting is illustrated by the Canaan Valley NWR CCP. The Refuge is one of a few that uses a staffand volunteer-operated ATV shuttle system to assist hunters in extracting harvested deer from remote areas of the Refuge. The shuttle system's trained operators can effectively minimize environmental harm, monitoring can be directed to the known time and places where the ORVs operate, and enforcement is relatively efficient.
Other Refuges, especially large ones, could adjust this technique to allow for their own distributed harvest, possibly transporting hunters to different areas of the Refuge along marked routes designated for this purpose. Although the Canaan Valley CCP did discuss the adverse physical environmental impacts from the ATV shuttle, it did not discuss the effect on the quality of the hunting experience.

Some Refuges provided narratives in the CCP to elaborate on their appropriateness findings. These varied from paragraphs (e.g., CCPs for Back Bay NWR, John Hay NWR, and Umbagog NWR) to page-long explanations (e.g., CCPs for Rappahannock River Valley NWR and Willamette Valley NWR Complex). These narratives provide greater insight into the FWS' rationale and assisted our understanding of the approach taken in the CCP; they would similarly assist the public and future Refuge managers. Currently, there is no national database collecting appropriateness analyses, which would permit comparisons and establish precedents. A compatibility-determination database exists for FWS staff, but is not accessible to the public. Upon promulgating the appropriate-uses policy, the FWS promised to "maintain a database of Refuge uses" in order to promote consistency (603 FW 1.11E). The policy envisioned the database as including "a refuge-byrefuge listing of all uses refuge managers have found either appropriate or not appropriate" (603 FW 1.11E). Such a database would address the persistent problem of coordination of Refuge units (Fischman 2007). Adding compatibility determinations to such a database might also save Refuge managers time because they could avoid duplicative analyses of ORV impacts in similar environmental contexts and on congruent visitor experiences.

In addition to better sharing of approaches to analysis of ORV recreation within the Refuge System, the FWS could also borrow from other public land managers that have more experience planning for ORV use. Compared with the FWS, the BLM and Forest Service land base open to ORV recreation is much larger, their plans court more controversy, their ORV use is increasing more rapidly, and the impacts of off-trail activities are greater. As a result, much of their planning guidance offers specific suggestions to improve site-specific impacts analysis of ORV recreation and management or restoration techniques to minimize and mitigate impacts.

California's terrain, concentration of public lands, and large population make it a particularly useful model for ORV recreation planning. The Forest Service's California region published a guidebook (USFS 2012) for implementing its travel analysis process, which is required for every forest that permits ORV recreation (50 C.F.R. §§ 212-261). The guidebook goes beyond simply listing and describing the categories of harms and benefits resulting from ORV recreation, though even that simple step would aid CCP analysis. It provides specific protocols for Geographic Information System analysis and data sets. It 
shows various ways that planners can reduce impacts without banning ORVs (e.g., through adjusting the seasons of use and maintenance of trails). These mitigation measures would be appropriate to include in compatibility stipulations. Perhaps the most useful aspect of the guidebook to Refuge planners is the specific metrics suggested for indicating impacts, including difficult-to-measure effects, such as fragmentation (USFS 2012, app. C). The BLM's West Mojave Plan environmental impact analysis illustrates applications of connectivity objectives in the context of conserving the endangered desert tortoise Gopherus agassizii in a place with significant ORV recreation (BLM 2005). Connecting CCP monitoring prescriptions to ORV impacts would improve compatibility determinations and facilitate adaptive management.

Once permitted with appropriate restrictions, ORV trails require maintenance to avoid unanticipated impacts, especially from erosion. The BLM handbook on primitive road design could be fruitfully employed in many CCPs to prescribe appropriate surveys, drainage elements, and road materials (BLM 2012). The Forest Service's California regional guidebook provides a calculator to show how many miles of routes can be maintained with a particular budget (USFS 2012, app. C). Because budgets across public land agencies are austere, the financial constraint is important to incorporate into plans. Monitoring, mitigation, and enforcement would also benefit from realistic allocations of expected cost to help planners understand the capacity of their units to support ORV use. Planning for volunteer and partner contributions to augment limited budgets would help clarify the conditions under which ORV recreation may occur, given the System's policy to deny uses that are "not manageable within the available budget and staff" (603 FW 2.10(D)(1)(f)).

An additional model for guidance on analyzing ORV impacts and mitigation is the soil conservation standards and guidelines for ORV use in California state parks (California State Parks 2008). Although the California parks may be more intensively used (particularly in designated motorized recreation areas) and better funded that NWRs, their standards and guidelines address the key concern of erosion and sustainability in ORV use. Where California state parks permit ORV recreation, they adopt protocols for assessments, monitoring, and compliance. Setting out those expectations in advance of a use approval is a reasonable way to align expectations of all interest groups and future public land managers. In particular, the California guidance would improve even the best existing CCP analyses through application of its monitoring protocols to 1) confirm whether activities were conducted as planned; 2 ) identify causes of erosion and sedimentation; 3) determine whether design, construction, and maintenance practices adequately meet objectives; and 4) characterize trends in conditions (California State Parks 2008, p. 22). Though conditions on many Refuges would not be suitable for the California guide, its menu of design and compliance details could direct Refuge planners to the key metrics for limiting ORV recreation to levels and places compatible with wildlife conservation. This would be particularly helpful given the relative lack of attention to soils issues in the NEPA analyses (Table 5).

\section{Best Management Practices and ORV Prescriptions}

Our study revealed a diverse set of management approaches that can be applied across a wide assortment of situations. Previous studies have generally focused on ORV use in a particular geographic area (e.g., Asah et al. 2012) or on a particular approach to managing ORVs (e.g., Mann and Leahy 2010). In contrast, we discuss the prescriptions that guide management of ORV recreation in Refuges across the United States. First, we compare the BMP literature with the manner in which CCPs address ORV use limitations and mitigation. Then we suggest ways in which CCP prescriptions for ORV use can be improved in future plans.

\section{BMP categories}

The literature on ORV use recommends a variety of BMPs (e.g., GAO 2009), which we organized into five common categories. We used these categories to sort the CCPs' approaches to managing ORV use and mitigating impacts. In this way, we attempted to close the gap between BMP types and actual applications of BMPs in conservation planning. Tables 6-10 show, for each BMP category, particular examples from CCPs. The tables also match each CCP example to a particular application of the category from the literature. Table 11 lists particular practices recommended in the literature that we did not find in any of the CCPs. It is possible that Refuges do practice some the applications listed in Table 11 but have simply not included them in CCPs, which vary in their level of documentation. We present the five categories in our BMP typology roughly in the order in which the FWS would apply them, beginning with policy formulation, through route planning, and then proceeding through permitting, monitoring, and enforcing.

The first of the five BMP categories-policy formation and public communication-focuses on creating maps, media campaigns, and other activities to involve ORV users in the management process (Table 6). Despite the absence of an update to the 1982 Refuge Manual policy on ORV use, the FWS already has a detailed policy framework created by the executive orders, the 1997 legislation, the regulation on compatibility, and the policies dealing with planning and appropriateness. Moreover, a CCP is not principally a policy-forming document. Therefore, the CCPs did not discuss this BMP very much. Nonetheless, the CCPs performed well in documenting the public outreach (including scoping) and partners engaged. Although there may be ORV user groups that were inadequately consulted, our study of just the CCP documents would not have identified them. 
Table 6. Best management practices for off-road vehicle (ORV) use related to policy formation and public communication, showing practices recommended in the peer-reviewed and agency-authored literature and examples of prescriptions for actions or practices from Comprehensive Conservation Plans (CCPs) written for national wildlife refuges in 2005-2011 that address ORV use, with the name of the refuge for which the prescription was written. For purposes of this study, ORVs included two- to six-wheel all-terrain vehicles, off-highway vehicles, utility vehicles, motorcycles, motorbikes, dune buggies, and snowmobiles.

\begin{tabular}{|c|c|c|}
\hline Literature review best management practice & CCP prescription (and page reference) & Refuge \\
\hline $\begin{array}{l}\text { Create a map for ORV users that includes } \\
\text { landscape features such as streams, topographic } \\
\text { information, and other trails that are specifically } \\
\text { labeled as closed to motor vehicles (GAO 2009). }\end{array}$ & $\begin{array}{l}\text { All trails are well-defined on hunt brochure } \\
\text { maps and are open only during periods of } \\
\text { hunting and fishing. (61) }\end{array}$ & Theodore Roosevelt Complex \\
\hline $\begin{array}{l}\text { Create mass media campaigns to educate the } \\
\text { local public about ORV issues and to gather } \\
\text { support. Publicize all progress and policy } \\
\text { updates (Archie 2007). }\end{array}$ & $\begin{array}{l}\text { The refuge will institute a public outreach } \\
\text { program (brochures, signs) to help educate the } \\
\text { public about refuge regulations, safety, and how } \\
\text { to minimize disturbance of wildlife. (C-51) }\end{array}$ & Umbagog \\
\hline
\end{tabular}

Route planning, the second BMP category, may also involve users, but concentrates on the specific criteria the Refuge will use to designate trails open to ORVs (Table 7). Zoning reserves for different uses is a core function of planning, and the executive orders (implemented through 8 Refuge Manual 7.8) require land managers to designate areas where ORVs are, and are not, permitted. Not surprisingly, then, route planning is the most common type of BMP found in CCPs, as reflected in the number of rows documented in Table 7. Route planning is generally spatial, but we also include in this category temporary closures to protect wildlife breeding sites. We also included the common call for managers to identify ORV routes with signage in this route-planning category. The executive orders and FWS manual require that ORV use be permitted only where impacts on natural resources are minimized. Route planning generally shoulders a large share of the minimization responsibility. Our review of CCPs reveals that the biggest challenge to developing routes and determining closures is the lack of site-specific impact analysis supporting minimization. The Forest Service guidance discussed in the previous section could help improve minimization planning.

The third BMP category, permitting, requires ORV trail users to take the initial step of registering with the Refuge, and sometimes even paying a fee (Table 8). The System is equipped and practiced in requiring certain users to obtain individual permission before engaging in a recreational activity. Like other dominant-use publicland systems, the Refuges are closed to all public use unless specifically, affirmatively permitted (50 C.F.R. § 25.21(a)). The three examples of CCP text requiring permits for ORV recreation are likely typical of all Refuges that are open to ORV use. Access to most of the nonAlaska Refuges is generally restricted by fencing or impassible terrain; therefore, permitting would be a particularly effective BMP. However, the open terrain of some large Refuges, such as Desert, makes permitting more difficult to enforce. As a result, the Desert NWR CCP responds by focusing more of its management prescriptions on detection and law enforcement. Absent from any of the CCPs we reviewed, however, was training and certification as a requirement for ORV use. Refuges are often created to conserve relatively sensitive habitats and declining species; therefore, training users to identify and avoid potential impacts holds potential for expanding the use of this category of BMPs.

The fourth category, monitoring (Table 9), is particularly important for implementing the adaptive management approach to Refuge planning promoted by the FWS and other resource agencies of the Department of the Interior (602 FW 3.4(C)(7); Williams et al. 2009). Despite the central role adaptive management plays in Refuge planning and management, we failed to find any CCP content that explained how ORV management would be subject to iterative adjustments as a result of learning through monitoring impacts. This is a major shortcoming of the CCPs because they are designed for periodic revision. Though Refuges may defer the development of monitoring protocols for subsequent step-down plans, we would expect to see the comprehensive plan at least identify key indicators of the impacts anticipated from ORV use, such as soil compaction, invasive species along routes, and wildlife mortality. The absence of such indicators in all but two CCPs suggests strongly that monitoring will not support the needs of adaptive management. The metrics and protocols of the Forest Service, BLM, and California State Parks are all good models for improving monitoring in the next round of CCPs.

Finally, enforcement of ORV prescriptions is a common category encountered in the literature and in CCPs (Tables 4, 10). One step in employing this BMP is identifying the parties involved in enforcement. Where Refuges abut multiple-use lands, such as in the lower Colorado River Valley, shared enforcement would seem feasible. Many Refuge units do not have even a single full-time FWS officer dedicated to their conservation. Therefore, enforcement of ORV prescriptions may depend on state wardens (e.g., Holla Bend CCP) or other local officers. The potential to employ volunteers or to plan increased patrols during seasons of greater ORV use were absent from the CCP documentation. They would be the next step for implementing this BMP. In addition, the CCPs did not discuss penalties, which are important 
Table 7. Best management practices for off-road vehicle (ORV) use related to route planning, showing practices recommended in the peer-reviewed and agency-authored literature and examples of prescriptions for actions or practices from Comprehensive Conservation Plans (CCPs) written for national wildlife refuges in 2005-2011 that address ORV use, with the name of the refuge for which the prescription was written. For purposes of this study, ORVs included two- to six-wheel all-terrain vehicles, off-highway vehicles, utility vehicles, motorcycles, motorbikes, dune buggies, and snowmobiles.

\begin{abstract}
Literature review best management practice
Locate ORV routes on upland, well-drained, coarse soil to prevent erosion and compaction. Add gravel to noncoarse soil, but avoid peat and other wet soils. (Wisconsin DNR 2005). Avoid placing routes above the tree line or near former mining sites (Switalski and Jones 2008).

Locate ORV routes away from water features and wetlands. If crossing a water feature or wetland is necessary, construct bridges, raised plank decking, turnpikes, or other structures to minimize the impact of the ORVs (Wisconsin DNR 2005)
\end{abstract}

Locate ORV routes in areas that do not contain sensitive, threatened, or endangered plant species or any unique plant communities to prevent their destruction (Switalski and Jones 2008).

Locate ORV routes in areas without invasive species or require that ORVs are washed upon leaving an area with invasive species (Switalski and Jones 2008).

Locate ORV routes in areas that do not contain critical habitat for sensitive, threatened, or endangered wildlife species to prevent the destruction of habitat and nests and the mortality of these species. Routes should also not be located near tunnels, caves, or mines on account of the bat populations that may reside there (Switalski and Jones 2008). Clearly identify all ORV routes with signage (Wisconsin DNR 2005; Archie 2007).

Close ORV routes during critical times for wildlife and vegetation such as the winter season and breeding season (Boyle and Samson 1985; Switalski and Jones 2008).

Place rocks, fences, or other barriers across access to nondesignated routes that may attract ORV users (GAO 2009).
Restricting use to designated trails routed to avoid

Catahoula sensitive areas, such as major stream crossings or archaeological areas, and opening most trails to season use only minimizes overall potential impacts. (47)

Trails will also be kept away from streams to avoid erosion. Where stream crossings are unavoidable, siting and construction of bridges or culverts will follow best management practices, and crossing structures will be maintained in good repair. (C-51)

Trails will be located away from areas of unique or sensitive vegetation, such as bogs or wetlands. (C-51)

Umbagog

Sampling equipment as well as investigator clothing Ankeny and vehicles (e.g., ATV, boats) will be thoroughly cleaned (free of dirt and plant material) before being allowed for use Refuge lands prevent the introduction and/or spread of pests. Where necessary, utilize quarantine methods. (C-67)

Snowmobile trails will be located so that they are away from deer wintering areas and do not run between deer bedding and feeding areas. (C-51)

There are also signs for No ATVs (all-terrain vehicles), Trail Closed, No Vehicles Beyond this Point. (54) Identify and mark beach-to-bay access routes for ORV use to protect important wildlife such as nesting birds and piping plovers. Access routes are intended only to support wildlife-dependent recreational uses. (4-10) Make sure that ATV trail signs clearly state that ATVs may be used for hunting purposes during specified times and that the trails can also be used for hiking, biking, etc. (87)

Identify and monitor snowy and Wilson's plover breeding sites for off-road vehicle (ORV) or human disturbance and establish seasonal closures on priority nesting areas. (4-8)

Within the nonrestricted areas of the refuge, the designated routes of travel end in established parking lot areas, which, in turn, have strategically placed barriers that prevent vehicles from being driven onto the foot trails, mangrove, or beach areas. (305)

Umbagog
Umbagog

Tensas River

Laguna Atascosa

Atchafalaya

Laguna Atascosa

Couna Atascosa

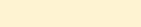

Trails will also be located in upland deciduous forest, Umbagog - 
Table 8. Best management practices for off-road vehicle (ORV) use related to permit requirements for ORV use, showing practices recommended in the peer-reviewed and agency-authored literature and examples of prescriptions for actions or practices from Comprehensive Conservation Plans (CCPs) written for national wildlife refuges in 2005-2011 that address ORV use, with the name of the refuge for which the prescription was written. For purposes of this study, ORVs included two- to six-wheel all-terrain vehicles, off-highway vehicles, utility vehicles, motorcycles, motorbikes, dune buggies, and snowmobiles.

\begin{tabular}{|c|c|c|}
\hline Literature review best management practice & CCP prescription (and page reference) & Refuge \\
\hline $\begin{array}{l}\text { Require a permit to use ORVs on public land. } \\
\text { The permits may be free to the user or require a } \\
\text { small fee. The manager can decrease illegal use } \\
\text { by gating routes and providing access codes to } \\
\text { those with permits. These permits increase rider } \\
\text { accountability and are generally acceptable to } \\
\text { the public (GAO 2009). }\end{array}$ & $\begin{array}{l}\text { An ATV user permit is required, and the permit must be } \\
\text { permanently affixed to the ATV used on the refuge. The } \\
\text { permit may be purchased at the visitor center or by mail for } \\
\text { US\$10. The refuge does have several trails for ATVs for hunters } \\
\text { with disabilities. Hunters with disabilities must have a } \\
\text { Physically Challenged Hunter Program Permit issued by the } \\
\text { LDWF or be } \geq 60 \text { y of age to operate an ATV on one of these } \\
\text { specially designated trails. (59) } \\
\text { All persons } \geq 16 \text { y of age must have a Catahoula Refuge } \\
\text { Hunting/Fishing permit in order to use an ATV on the refuge. } \\
\text { (137) } \\
\text { After selected ATV trails have been restored, establish an ATV } \\
\text { use permit fee to cover trail maintenance and program } \\
\text { management. Monies obtained from this fee will be } \\
\text { specifically used for maintenance of existing ATV trails. (121) }\end{array}$ & $\begin{array}{l}\text { Catahoula } \\
\text { Theodore Roosevelt } \\
\text { Complex }\end{array}$ \\
\hline
\end{tabular}

in deterrence, notwithstanding the alternative approaches suggested in the literature (e.g., Archie 2007; GAO 2009).

\section{Improving ORV prescriptions}

Planning for suitable, low-impact, recreational ORV use is the ultimate goal of the management tools we have discussed and identified in the CCPs. In general, the analyses of ORV use contained in CCPs focus on how management can limit adverse impacts where ORV use is considered appropriate and compatible. The resulting limitations on legal ORV use become important prescriptions for the Refuge managers responsible for implementing plans.

The literature confirms that restrictions on ORV use can minimize adverse environmental impacts (e.g., Lucrezi et al. 2014). However, even outright bans may fail to avoid harms if ORV use persists. Several CCPs that identify illegal ORV use do not contain responsive prescriptions. The Desert NWR is a good example of how a CCP can briefly yet effectively address illegal use in prescriptions. The CCP prohibits ORV use as inappropriate, but documents increasing unauthorized ORV use that damages the soil, natural hydrology, and meadow habitats. The Desert NWR CCP prescribes installation of signs, barricades, and fencing to prevent access by ORVs, particularly in areas where illegal trails have been created. It states that law enforcement will patrol the Refuge to enforce the ORV prohibition. The CCP also prescribes use of aerial photography, satellite imagery, and Global Positioning System to monitor damage from ORV trespasses. Monitoring could usefully be a more widely adopted prescription where illegal use is an issue because it facilitates adjustment of enforcement strategies in response to observed results. Documentation of harm from illegal use may be important in levying fines and other punishments to deter future activity. Physical barriers, such as barricades and fencing, though potentially costly, are especially important where fines for violators of ORV rules may not provide sufficient deterrence.

Where CCPs permit ORV use to facilitate hunting, more detailed prescriptions might better ensure that Refuges achieve their goals for wildlife-dependent recreation while minimizing the adverse effects on wildlife, habitat, and other visitors. The FWS' own handbook on "Writing Refuge Management Goals and Objectives" recommends that CCPs establish specific, measurable, achievable, time-limited objectives for their prescriptions (Adamcik et al. 2004, 602 FW 3). Greater attention to ORV management in CCP prescriptions, particularly through measurable objectives, would provide clearer benchmarks for expanding or contracting their use. Many CCPs address ORV use only in the compatibility determinations collected in an appendix. Stipulations listed in these determinations that seek to protect Refuge resources from ORV impacts may not be reflected in the prescriptive text of the CCPs and, as a result, may be overlooked in adaptive management processes.

Careful analysis of impacts, along with detailed prescriptions, in CCPs support managers who seek to maintain wildlife protection against increasing pressure to provide more recreational opportunities. Prescribed management of ORV activities generally benefits from consideration of all five categories of BMPs: policy formation and public participation, spatial and temporal route planning, permitting, monitoring, and enforcement. The examples of CCP prescriptions that apply particular BMPs in Tables 6-10 are a starting point for sharing specific applications of each of the five categories. In partnership with other agencies, the FWS could maintain a comprehensive collection of applications of BMPs in a database of case-examples accessible to both managers and researchers. The Ecosystem 
Table 9. Best management practices for off-road vehicle (ORV) use related to monitoring impacts of ORV use, showing practices recommended in the peer-reviewed and agency-authored literature and examples of prescriptions for actions or practices from Comprehensive Conservation Plans (CCPs) written for national wildlife refuges in 2005-2011 that address ORV use, with the name of the refuge for which the prescription was written. For purposes of this study, ORVs included two- to six-wheel all-terrain vehicles, off-highway vehicles, utility vehicles, motorcycles, motorbikes, dune buggies, and snowmobiles.

Literature review best management practice
Regularly monitor soil on ORV routes for erosion and
compaction and close routes for restoration when
deemed necessary (Switalski and Jones 2008).
Regularly monitor vegetation along ORV routes for
damage, uprooting, and spread of invasive species and
close routes for restoration when deemed necessary
(Switalski and Jones 2008).
Regularly monitor wildlife along ORV routes for
moralities, destruction of nests, reduction of
reproduction, and presence of threatened or
endangered species and close routes for restoration
when deemed necessary (Switalski and Jones 2008).
Make use of proven monitoring technologies including
remote electronic monitoring (seismic, infrared, or
magnetic detectors) to detect illegal use and decibel
meters to monitor for noise violations. Video
surveillance can be used to identify repeat offenders
and aerial photography can track the location and
spread of illegal routes (Archie 2007).

CCP prescription (and page reference)
All trails will be surveyed for signs of wildlife activity,
sensitive vegetation, or erosion potential, and trail
locations will be entered into a geographic information
system. We will use that information to guide routing,
rerouting, or closure of trails. Biological inventories will
continue to provide baseline information for measuring
change. Should the monitoring and evaluation of the
use indicate that the compatibility criteria have or will
be exceeded, appropriate action will be taken to ensure
continued compatibility, including modifying or
discontinuing the use. (C-51)

Use aerial photography, satellite imagery, and/or Global Positioning System to monitor damage caused by offroad vehicle trespass on refuge lands. (F-30)

\author{
Umbagog
}

Management Initiative's searchable database of collaborative ecosystem management case studies offers a useful model (http://www.snre.umich.edu/ecomgt// cases/entry.htm). Curated collections of BMP applications may promote further research on implementation and effectiveness of management tools.

The most important lesson from the BMP literature is the importance of involving stakeholders. All Refuges, even large ones, can gain through engagement with neighbors to coordinate ORV management efforts. The ORV prescriptions we studied did not detail how coordination across property boundaries would occur. Prescriptions for acting outside the Refuge are an important part of the biological goals of CCPs, and CCPs perform well in crafting cross-boundary activities for biological objectives (Meretsky and Fischman 2014). Extension of the landscape-scale planning tools to recreational objectives would yield similar benefits. For instance, $60 \%$ of CCPs use North American Bird Conservation Initiative plans to justify prescriptions for wildlife and habitat (Meretsky and Fischman 2014:1422). It may be possible to use those plans to coordinate

Table 10. Best management practices for off-road vehicle (ORV) use related to enforcement of ORV regulations, showing practices recommended in the peer-reviewed and agency-authored literature and examples of prescriptions for actions or practices from Comprehensive Conservation Plans (CCPs) written for national wildlife refuges in 2005-2011 that address ORV use, with the name of the refuge for which the prescription was written. For purposes of this study, ORVs included two- to six-wheel all-terrain vehicles, off-highway vehicles, utility vehicles, motorcycles, motorbikes, dune buggies, and snowmobiles.

\begin{tabular}{ll}
\hline Literature review best management practice & \multicolumn{1}{c}{ CCP prescription (and page reference) } \\
\hline $\begin{array}{l}\text { Create a partnership with local law enforcement } \\
\text { to issue penalties for ORV policy violation } \\
\text { (Switalski and Jones 2008, Archie 2007). }\end{array}$ & $\begin{array}{l}\text { Enforcement of refuge regulations to protect trust resources and } \\
\text { provide for a quality recreational opportunity will occur via regular } \\
\text { patrols by refuge law enforcement officers. (136) }\end{array}$ \\
& \\
$\begin{array}{l}\text { Utilize volunteers and local law enforcement to } \\
\text { increase routine patrolling and scale up } \\
\text { patrolling efforts during times and seasons when } \\
\text { violations are most likely to occur (Archie 2007; }\end{array}$ & $\begin{array}{l}\text { Enforcement of refuge regulations to protect trust resources and } \\
\text { provide for a quality recreational opportunity will occur via regular } \\
\text { Albritton et al. 2009; GAO 2009). }\end{array}$ \\
$\begin{array}{l}\text { not have a law enforcement officer on staff. Law enforcement support } \\
\text { is provided from surrounding refuge field stations. Additionally, } \\
\text { personnel from the [Arkansas Game and Fish Commission] will patrol } \\
\text { the refuge and assist refuge officers when needed. (135) }\end{array}$ \\
\hline
\end{tabular}


Table 11. Best management practices for off-road vehicle (ORV) recommended in the peer-reviewed and agency-authored literature for which no examples occurred in Comprehensive Conservation Plans (CCPs) written for national wildlife refuges in 2005-2011. For purposes of this study, ORVs included two- to six-wheel all-terrain vehicles, off-highway vehicles, utility vehicles, motorcycles, motorbikes, dune buggies, and snowmobiles.

\begin{tabular}{ll}
\hline BMP category & \multicolumn{1}{c}{ Particular practice(s) } \\
\hline $\begin{array}{l}\text { Policy formation and } \\
\text { public communication }\end{array}$ & Engage stakeholders such as the local public and environmental groups in policy-making to gain input from \\
& multiple perspectives and to better ensure adoption of the finalized policies (U.S. Institute for Environmental \\
& Conflict Resolution 2005). \\
- & Design signage in conjunction with ORV groups as a way to reduce vandalism and off-route driving because \\
& ORV users are given a stake in the signage and feel more involved in the decision process (GAO 2009). \\
- Locate ORV routes on slopes with a 0-5\% incline. Avoid slopes that have an incline $>15 \%$. Armor inclines & \\
Route planning & with cinder blocks to reduce erosion (Wisconsin DNR 2005; Switalski and Jones 2008). \\
& Locate ORV routes away from hiking, biking, and equestrian trails to prevent conflicts with other recreational \\
& - Create routes in areas that are enforceable, such as areas that are close to the visitor center (Archie 2007).
\end{tabular}

Permitting Require that ORV users undergo a training course and receive certification (Archie 2007).

Monitoring Monitor other areas of the NWR to ensure there is no illegal ORV use taking place (Switalski and Jones 2008).

Enforcement - Enhance funding and expand the capacity of the staff to enforce policies (Archie 2007).

- Make penalties tough and escalate them when offenses are repeated. Maintain a database of violations (Archie 2007). Penalties may include arrest, fine, community service requirement, ORV impoundment, or revocation or suspension of ORV use or other refuge privileges (Archie 2007, GAO 2009).

lowest-impact routes for ORV users. Where the neighbors are other federal agencies, close cooperation may include shared databases, BMP approaches, and enforcement personnel. The BLM and Forest Service, in particular, have devoted considerable resources to travel allocations and route locations that minimize potential harm to biological resources (Adams and McCool 2009). The FWS has less ORV activity and considerably fewer personnel to manage ORV recreation. Nonetheless, it may benefit from the studies, mitigation approaches, and enforcement staff of its sister agencies. Other neighbors, some with even more dramatically different objectives for land use than multiple-use agencies, pose even more challenging barriers to cooperation.

A key collaborative conservation principle is that social capital helps land managers to work with recreationists (Mann and Leahy 2010). Neighbors who invest time collaborating on ORV management prescriptions in a CCP are apt to be more active in monitoring and enforcement. So are clubs of ORV recreationists, who both set and enforce norms, such as proscribing drunkenness or littering, among users. Clubs are sometimes active in patrolling trails as volunteers, an expression of the second enforcement BMP in Table 10. All the CCPs document extensive engagement with neighbors, recreationists, and conservation groups in the course of developing the plan. But social capital requires both interdependence (the FWS and the outside groups need each other to achieve common objectives) and expectations of cooperative actions, which strengthen through trust developed over time (Pretty and Ward 2001; Davenport et al. 2007). Therefore, stronger plans would provide a framework for continual interaction with the groups that participated in the formation of the plans. Where local ORV clubs exist, they may have access to additional monies for trail maintenance through state grants and club fees. Where clubs are absent, NWR friends groups may have the access to social networks that could support many of the functions of recreationist clubs. Either group would help disseminate the information that ORV users need in order to find appropriate routes and use them in a way that advances the purposes of stipulations limiting damage. When a plan lays out specific actions that would sustain trust and continued collaboration on ORV issues, we expect they are more likely to be implemented and monitored. Therefore, we might add to the BMPs found in the literature one that focuses specifically on building social capital in the service of better plan implementation.

\section{Supplemental Material}

Please note: The Journal of Fish and Wildlife Management is not responsible for the content or functionality of any supplemental material. Queries should be directed to the corresponding author for the article.

Table S1. Contains two workbooks. Workbook S1 presents the findings of appropriateness and compatibility for off-road vehicle (ORV) uses from the 42 Comprehensive Conservation Plans (CCPs) for National Wildlife Refuges completed between 1 January 2005 and 1 January 2012 that mention ORV impacts. In total, 185 CCPs were completed for named Refuges during this time. Bans on ORV use on National Wildlife Refuges do 
not require findings of appropriateness or compatibility determinations. A finding of appropriateness is not needed for ORV use if part of wildlife-dependent recreation (hunting, fishing, wildlife photography, wildlife observation, environmental education, interpretation) but a compatibility determination is needed. For purposes of this study, ORVs included two- to six-wheel all-terrain vehicles, off-highway vehicles, utility vehicles, motorcycles, motorbikes, dune buggies and snowmobiles. Where uses of different kinds of ORVs were subject to separate findings and determinations in a given CCP, we list those results on separate lines.

Workbook S2 in Table S1 presents the numbers of mentions of ORV-related topics in environmental impact statements and environmental assessments prepared for 42 Comprehensive Conservation Plans (CCPs) for National Wildlife Refuges completed between 1 January 2005 and 1 January 2012 that mention ORVs. In total, 185 CCPs were completed for named wildlife refuges during this time. For purposes of this study, ORVs included two- to six-wheel all-terrain vehicles, offhighway vehicles, utility vehicles, motorcycles, motorbikes, dune buggies and snowmobiles. $0=$ topic not considered; $1=$ topic mentioned in context not suitable for codes 2-6; 2 = topic mentioned in public comment; 3 = topic raised in discussion of ORV use for refugemanagement purposes (refuge-management use of ORVs does not require either a finding of appropriateness or a determination of compatibility); $4=$ topic mentioned in a goal, objective or strategy (collectively called "prescriptions"); 5 = topic mentioned in discussion of ORV use for research; $6=$ discussion of minimization or mitigation practices showing a consideration of effects but not specifically noting direct effects from ATV use (e.g., after applying pesticides, spraying off ATVs to prevent the spread of the pest throughout the refuge). If multiple codes apply, they are all shown, separated by commas.

Found at DOI: http://dx.doi.org/10.3996/052016JFWM-040.S1 (17 KB DOCX).

\section{Acknowledgments}

The FWS (especially Ross Alliston and Ben Blom) and Marc Lame provided help in research and analysis. Wendy Anderson, Jenn Teson, and Ryan Weiss provided research assistance. Our spring 2012 Indiana University capstone class assisted in coding plans and interpreting data. Finally, we thank the two anonymous peer reviewers, Jim Weigand, and the JFWM Associate Editor, whose careful suggestions significantly improved this article.

Any use of trade, product, or firm names is for descriptive purposes only and does not imply endorsement by the U.S. Government.

\section{References}

Adamcik RS, Bellantoni ES, DeLong DC Jr, Schomaker JH, Hamilton DB, Laubhan MK, Schroeder RL. 2004. Writing refuge management goals and objectives: a handbook. Washington, D.C.: U.S. Fish and Wildlife Service. Available: www.fws.gov/refuges/policiesandbudget/ pdfs/writingrefugegoals_022504.pdf (October 2016).

Adams JC, McCool SF. 2009. Finite recreation opportunities: the Forest Service, the Bureau of Land Management, and off-road vehicle management. Natural Resources Journal 49:45-116.

Albritton R, Taylor VS, Thapa B. 2009. Exploring conflict and tolerance between and within off-highway vehicle recreationists. Journal of Park and Recreation Administration 27:54-72.

Archie ML. 2007. Six strategies for success: effective enforcement of off-road vehicle use on public lands. Missoula, Montana: Wildlands CPR. Available: http:// www.wildearthguardians.org/site/DocServer/ SixStrategiesReport.pdf?docID=9963\&AddInterest=1304 (October 2016).

Asah ST, Bengston DN, Wendt K, DeVaney L. 2012. Prognostic framing of stakeholders' subjectivities: a case of all-terrain vehicle management on state public lands. Environmental Management 49:192-206.

Banha F, Marques M, Anastacio PM. 2014. Dispersal of two freshwater invasive macroinvertebrates, Procambarus clarkii and Physella acuta, by off-road vehicles. Aquatic Conservation: Marine and Freshwater Ecosystems 24:582-591.

Boyle SA, Samson FB. 1985. Effects of nonconsumptive recreation on wildlife: a review. Wildlife Society Bulletin 13:110-116.

California State Parks. 2008. Off-Highway Motor Vehicle Recreation Division. Soil conservation standard and guidelines. Available: http://ohv.parks.ca.gov/pages/ 1140/files/2008\%20soil\%20cons.\%20standard\%20 and\%20guidelines.pdf (January 2017).

[CRS] Congressional Research Service. 2013. Motorized recreation on National Park Service lands. R42955. Available: www.fas.org/sgp/crs/misc/R42955.pdf (October 2016).

Cordell HK, Betz CJ, Green G, Stephens B. 2008. Offhighway vehicle recreation in the United States and its regions, and states: a national report from the National Survey on Recreation and the Environment (NSRE). Asheville, North Carolina: U.S. Department of Agriculture Forest Service. Internet Research Report Series. Available: www.fs.fed.us/recreation/programs/ohv/ IrisRec1rpt.pdf (October 2016).

Cordell HK, Betz CJ, Zarnoch SJ. 2013. Recreation and protected land resources in the United States: a technical document supporting the Forest Service 2010 RPA assessment. Asheville, North Carolina: U.S. Department of Agriculture Forest Service. General Technical Report SRS-GTR-169. Available: http://www. srs.fs.usda.gov/pubs/42756 (October 2016).

Davenport J, Switalski TA. 2006. Environmental impacts of transport, related to tourism and leisure activities. Pages 333-360 in Davenport J, Davenport JL, editors. 
The ecology of transportation: managing mobility for the environment. Netherlands: Springer.

Davenport MA, Leahy JE, Anderson DH, Jakes PJ. 2007. Building trust in natural resource management within local communities: a case study of the Midewin National Tallgrass Prairie. Environmental Management 39:353-368.

Deisenroth D, Loomis J, Bond C. 2009. Non-market valuation of off-highway vehicle recreation in Larimer County, Colorado: implications of trail closures. Journal of Environmental Management 90:3490-3497.

Eberle LS. 2015. Minimization criteria for off-road vehicle use. Michigan Journal of Environmental \& Administrative Law 5:257-288.

EO [Executive Order No.] 11644. 1972. 37 Federal Register 2877. Available: www.archives.gov/federal-register/ codification/executive-order/11644.html (October 2016).

EO [Executive Order No.] 11989. 1977. 52 Federal Register 34617. Available: www.archives.gov/federal-register/ codification/executive-order/11644.html (October 2016).

Fischman R. 2003. The national wildlife refuges: conserving a conservation system through law. Washington, D.C.: Island Press.

Fischman R. 2007. From words to action: the impact and legal status of the 2006 national wildlife refuge system management policies. Stanford Environmental Law Journal 26:77-135. Available: http://papers.ssrn.com/ sol3/papers.cfm?abstract_id=921073\&download=yes (October 2016).

Havlick DG. 2002. No distant place: roads and motorized recreation on America's public lands. Washington, D.C.: Island Press.

Jakus PM, Keith JE, Liu L, Blahna D. 2010. The welfare effects of restricting off-highway vehicle access to public lands. Agricultural and Resource Economics Review 39:89-100.

Lucrezi S, Saayman M, van der Merwe P. 2014. Impact of off-road vehicles (ORVs) on ghost crabs of sandy beaches with traffic restrictions: a case study of Sodwana Bay, South Africa. Environmental Management 53:520-533.

Mann M, Leahy J. 2010. Social capital in an outdoor recreation context. Environmental Management 45:363-376.

Marion DA, Philips JD, Yocum C, Mehlhope SH. 2014. Stream channel responses and soil loss at off-highway vehicle stream crossings in the Ouachita National Forest. Geomorphology 216:40-52.

Melvin SM, Hecht A, Griffin CR. 1994. Piping plover mortalities caused by off-road vehicles on Atlantic coast beaches. Wildlife Society Bulletin 22:409-414.

Meretsky VJ, Fischman RL. 2014. Learning from conservation planning for the U.S. national wildlife refuges. Conservation Biology 28:1415-1427.

Monz CA, Cole DN, Leung Y, Marion JL. 2010. Sustaining visitor use in protected areas: future opportunities in recreation ecology research based on the USA experience. Environmental Management 45:551-562.

National Wildlife Refuge System Improvement Act. 1997. Pub. L. No. 105-57, 111 Stat. 1252 (Oct. 9, 1997). Available: https://www.gpo.gov/fdsys/pkg/PLAW105publ57/content-detail.html (March 2017).

Pickering CM, Hill W, Newsome D, Leung YL. 2010. Comparing hiking, mountain biking and horse riding impacts on vegetation and soils in Australian and the United States of America. Journal of Environmental Management 91:551-562.

Pretty J, Ward H. 2001. Social capital and the environment. World Development 29:209-227.

Reed SE, Merenlender AM. 2008. Quiet, nonconsumptive recreation reduces protected area effectiveness. Conservation Letters 1:146-154.

Stokowski PA, LaPointe CB. 2000. Environmental and social effects of ATVs and ORVs: an annotated bibliography and research assessment. Burlington: University of Vermont, School of Natural Resources. Available: www.nature.nps.gov/sound/assets/docs/ ohvbibliogVT00.pdf (October 2016).

Switalski TA, Jones A, editors.2008. Best management practices for off-road vehicle use on forestlands: a guide for designating and managing off-road vehicle routes. Missoula, Montana: Wildlands CPR. Available: http:// www.wildearthguardians.org/site/DocServer/ORV_BMP_ 2008_0.pdf?docID=10443\&Addlnterest=1304 (October 2016).

Switalski TA, Jones A. 2012. Off-road vehicle best management practices for forestlands: a review of scientific literature and guidance for managers. Journal of Conservation Planning 8:12-24.

Trombulak SC, Frissell CA. 2000. Review of ecological effects of roads on terrestrial and aquatic communities. Conservation Biology 14:18-30.

[BLM] U.S. Department of the Interior Bureau of Land Management. 2005. Final Environmental Impact Report and Statement for the West Mojave Plan, vol. 1. Available: https://www.blm.gov/ca/pdfs/cdd_pdfs/ wemo_pdfs/plan/wemo/Vol-1-Chapter1_Bookmarks. pdf (January 2017).

[BLM] U.S. Department of the Interior Bureau of Land Management. 2012. Primitive roads design handbook (9115-1). Available: https://www.blm.gov/style/medialib/ $\mathrm{blm} /$ wo/Information_Resources_Management/policy/ blm_handbook.Par.78726.File.dat/H-9115-1.pdf (January 2017).

[USDA] U.S. Department of Agriculture Forest Service. 2006. Four threats to the health of the nation's forests and grasslands. Available: www.fs.fed.us/projects/fourthreats/ (October 2016).

U.S. District Court. 2012. Wilderness Society v. U.S. Forest Service, 850 F.Supp.2d 1144 (D. Idaho).

U.S. District Court. 2013. Wilderness Society v. U.S. Forest Service, 2013 WL 5729056 (D. Idaho) No. CV08-363-EEJL. 
[USFS] U.S. Forest Service. 2012. Travel analysis process: a guidebook. Guidance for Region 5 forests to complete travel analysis. Available: https://www.fs.usda.gov/ main/r5/recreation/travelmanagement (January 2017).

[USFWS] U.S. Fish and Wildlife Service. 2000. Final Compatibility Policy Pursuant to the National Wildlife Refuge System Improvement Act of 1997. Federal Register 65:62,484-62,496.

[USFWS] U.S. Fish and Wildlife Service. 2006. Off-road vehicle use on national wildlife refuges, Memorandum from the Director to the Service Directorate. Washington, D.C.: U.S. Department of the Interior Fish and Wildlife Service.

[USFWS] U.S. Fish and Wildlife Service. 2014. NEPA for National Wildlife Refuges: a handbook. Available: https://www.fws.gov/policy/NEPARefugesHandbook. pdf (January 2017).

[USFWS] U.S. Fish and Wildlife Service. 2015. Annual report of lands: statistical data tables. Available: www. fws.gov/refuges/land/PDF/2015_Annual_Report_of_ LandsDataTables.pdf (October 2016).

[GAO] U.S. General Accounting Office. 1981. National direction required for effective management of America's fish and wildlife. CED-81-107. Available: http://gao.gov/products/CED-81-107 (October 2016).
[GAO] U.S. General Accounting Office. 1989. National wildlife refuges: continuing problems with incompatible uses call for bold action. RCED-89-196. Available: www.gao.gov/products/RCED-89-196 (October 2016).

[GAO] U.S. Government Accountability Office. 2009. Federal lands: enhanced planning could assist agencies in managing increased use of off-highway vehicles. GAO-09-509. Available: www.gao.gov/new. items/d09509.pdf (October 2016).

U.S. Institute for Environmental Conflict Resolution. 2005. Off-highway vehicle use and collaboration: lessons learned from project implementation. U.S. Department of Agriculture, Forest Service; and Morris K. Udall Foundation. Available: www.fs.fed.us/recreation/ programs/ohv/CaseStudyReport.pdf (October 2016).

Williams BK, Szaro RC, Shapiro CD. 2009. Adaptive management: the U.S. Department of the Interior technical guide (updated edition). U.S. Department of the Interior. Available: https://www.doi.gov/sites/doi. gov/files/migrated/ppa/upload/TechGuide.pdf (October 2016).

Wisconsin [DNR] Department of Natural Resources. 2005. So you want to build an ATV trail: a practical guide for evaluating potential for trail grant sponsors. Available: http://dnr.wi.gov/Aid/documents/atv/BuildATVTrail. pdf (October 2016). 